\title{
Intellectual cross-fertilization and evolution
}

\section{A.J. Cain}

The Evolutionary Synthesis: Perspectives on the Unification of Biology. Edited by Ernst Mayr and William B. Provine. Pp.487. ISBN 0-674-27225-0. (Harvard University Press: 1980.) \$25, £15.

THIS book looks out upon an incredibly rich panorama of personalities, groups, institutions, countries, attitudes, theories, arguments, experiments, facts, false facts (even a very few artefacts), misunderstandings, barriers emotional, linguistic, dogmatic and intellectual, all adding up to one of the greatest intellectual advances of our time - the unification of different biological sciences by a single neoDarwinian theory of evolution in the first half of this century. Some of the principal actors have contributed invaluable accounts of their own roles: among them are Mayr, Simpson, Dobzhansky, E.B. Ford, C.D. Darlington, Curt Stern; and there are extremely valuable surveys and analyses by biologists, historians and philosophers (Lewontin, Gould, Mark Adams, Dudley Shapere etc.). The book itself is now history and, since the 1900-1940 period qualifies as history (not merely as out-of-date), it will inspire and provoke an ebullition of $\mathrm{PhD}$ theses, papers and books worse than the great Wittgenstein industry. One of the virtues of the book is that while making thoroughly clear the limitation of science by the inadequacies of personalities, institutions and governments, it does present beautifully, especially in genetics and cytology, the intellectual impact of actual scientific discoveries and their role in changing people's thinking.

The book is organized by subjects (Part I, cytology, embryology, systematics, botany and so on) and by countries (Part II, Russia, Germany, England, France, USA), with a concluding survey (no, I will not say "overview") of the whole subject and a miscellany of very useful biographical contributions, rather over-titled as "Biographical Essays".

Especially valuable to those with little German and less Russian is the survey by countries, and a saddening spectacle it presents; the superb beginning in Russia, based on an excellent naturalists' tradition of population genetics, aided at first by the ideals of education and especially science during the Revolution, then brutally terminated as a result of the charlatan Lysenko's power-politics. France did not contribute at all to the synthesis except for Teissier's and L'Heritier's invention of the population cage and work on balanced polymorphisms. Both started as mathematicians (the probable reason for Teissier getting his chair at the Sorbonne is fascinatingly non-scientific), uncontaminated by the ideas of the French Establishment.
Both Boesiger and Limoges have some very hard things to say about the academic establishment in France, and, so far as I can see, they are thoroughly justified. Boesiger remarks "France today (1974) is a kind of living fossil in the rejection of modern evolutionary theories; about 95 percent of all biologists and philosophers are more or less opposed to Darwinism."

Limoges comments equally astringently on the language barrier, the closed university system ("no one can hold a chair in a French university who is not French and who does not have a French doctorate') and the centralization of the system, providing for career control by a few senior professors in Paris. Although that has now been considerably modified, Boesiger emphasizes the centralized control of the research organizations. One can add that there is considerable pressure on French workers to publish in French. Certainly there are in France today some excellent and up-to-date evolutionists - one thinks immediately of Maxime Lamotte in Paris, and a botanical group at CNRS Montpellier, as well as Zuckerkandl and others at that university; nevertheless it seems to be true that a largely self-perpetuating Establishment, accepting only conformist successors, has made France, as far as evolutionary studies go, into an intellectual island. Yet the new recruitment every year of fresh minds is one of the most valuable processes in any intellectual society.

Germany is well treated by Mayr, Rensch and Hamburger. Mayr brings out important administrative limitations (not enough chairs and the nature of professional duties), Curt Stern the difficulties of institutions separated by distance (BerlinBuch and Berlin-Dalhem!). Little is said about Nazi influence. Rensch, in an essay very sympathetic to his predecessors and colleagues, brings out many reasons for the slowness of the synthesis in Germany apparently contradictory phenomena in genetics and palaeontology, speciation apparently concerned only with trivial characters, the apparent internal drive of the organism in development and regulation, independent of the environment, religious convictions and so on, which, however, operated elsewhere as well. The slowness of penetration of genetical results in Germany certainly needs study.

Hamburger brings out a further point (which Boesiger applies also to Cuénot in France): "the widespread German tendency to have a unified Weltanschauung, a more general overview of metaphysical and scientific creeds than just having Weltanschauung and scientific work compartmentalized side by side".

The history of the evolutionary synthesis in the USA is particularly well treated, and deservedly so, and there are many studies of that intriguing man T.H. Morgan and
Minerals from the Marine Environment

Sir Peter Kent, FRS

Resource and Environmental Sciences Series

A review of the full spectrum of mineral resources development as seen against the environmental background of the seas and oceans

£3.95 paper 96 pages

\section{The Ecology of Natural Resources}

Second Edition

\section{I.G. Simmons}

The author has strengthened the new edition both by updating it statistically and by changing it conceptually. Increased emphasis is given to energy as a resource and as a link with other resource processes.

$£ 8.50$ paper 448 pages

Additions to the Studies in Biology series:

124 Light and Plant Life J.M. Whatley and F.R. Whatley, FRS $£ 2.75$ paper 96 pages

125 Lipids and Polysaccharides in Biology

Anna J. Furth $£ 2.10$ paper 72 pages

126 Bioenergetics of Autotrophs and Heterotrophs

John W. Anderson $£ 1.95$ paper 64 pages

\section{Invertebrate} Respiration

Rufus M.G. Wells $£ 2.25$ paper 76 pages

128 Immunobiology Christopher J. Inchley $£ 2.50$ paper 80 pages

129 Growth Regulators in Crop Production Leonard C. Luckwill £1.95 paper 64 pages

\section{Edward Arnold} 41 Bedford Square, London WC1B 3DQ 
his close associates. The conversion of this school to a neo-Darwinian attitude by their own discoveries in genetics and karyology, powerfully aided by their openness to ideas and visitors from abroad, was, however, only partial in some cases because of the difficulties of extending genetical findings to macroevolutionary phenomena, including speciation. Mayr makes an especially important contribution in emphasizing that the synthesis was a synthesis; it was extremely difficult for many years to reconcile Darwinism and the new science of genetics, and it was systematists in particular who contributed the concepts of adaptive geographical variation, variation in whole populations under environmental selection, and partly adaptive speciation (a macroevolutionary process). Yet it must be added that it was largely the wholly unjustified insistence of many systematists that characters of species were nonadaptive that misled many of the earlier evolutionists into doubts about the efficacy of natural selection and the continuity of micro- and macroevolutionary phenomena.

Equally fascinating is the comparison between subjects. Botany (not the botanical part of genetics) was almost as poor a contributor among subjects as France among countries, and Ledyard Stebbins's article is as thought-provoking as Boesiger's or Limoges'.

When one stands back from it all, several major thoughts come to mind. The difficulties are highly instructive, but little more than one would expect in any intellectual controversy; indeed Simpson is probably right in indicating that given the human character, the synthesis was achieved about as fast as could be expected. But some topics are hardly touched on. I suspect (in a few instances, I know) that religious considerations came first, even if they were seldom expressed, in some scientists' minds, and conditioned heavily what they were prepared to accept scientifically. Under this heading I include humanism when it refuses the application of the synthesis to mankind, and of course Marxism with its leaning to some form of Lamarckism (only too well documented in this book).

Secondly, and allied to the preceding, the role of chance as an explanatory factor is hardly touched on - yet, on the one hand, as a means of explaining away inconvenient phenomena it has been invaluable as an alternative to natural selection; on the other, it has added to the revulsion of many people against natural selection that what the process has to work on is the effects of mere chance.

But lastly, there is almost no indication in the book that the recognition of natural selection as the major (or nearly exclusive) agent of evolution was ever due to any work on natural selection in the wild, except very indirectly. A simple-minded (or extremely intelligent) Martian might well think that if it was debated whether natural selection operated in the wild, the thing to do was to go and look for it. Chetverikov might have done so if politicians had let him; Haldane thought it much too difficult. The whole debate over the efficiency of natural selection in the wild was conducted by argument over indirect evidence, and indeed to a large extent it still is.

The present book contains little material towards a history of actual field-work directly on natural selection, except for E.B. Ford's contribution - and perhaps rightly, since it seems not to have affected the synthesis. It does contain valuable hints towards a history of why no one has attempted it - for example, Lewontin's statement that "Wright's notion that random processes allow the exploration of the field of gene frequencies ... frees the evolutionist from having to ask such questions as why did some Ceratopsian dinosaurs have three horns and some have two and some have a frill and some not?". Of course it does nothing of the sort except to those who want it to. It was not shown in the first place that the development of different ways of fighting was due to any random process, except on the presumptuous assertion "Because I can see no sense in this phenomenon, not having worked on it, therefore it must be random". The use of random processes in explanation even at the present day is rather like John Henry Newman's use of St Augustine's text to precipitate him into the Roman Catholic church (see Geoffrey Faber's Oxford Apostles) - using a bad reason for doing what we intend to anyway.

A.J.Cain is Derby Professor of Zoology in the University of Liverpool.

\section{Avian evolution transcends philately}

\section{Alec Panchen}

The Age of Birds. By Alan Feduccia. Pp.208. ISBN 0-674-00975-4. (Harvard University Press: 1980.) £12, \$20.

OF ALL those who concern themselves with the palaeontology and evolution of vertebrate animals, it is arguable that bird palaeontologists have taken on the most difficult task. The anatomical uniformity of the majority of bird species is such that the identification of their individual fossil bones varies between difficult and impossible; further, there are numbers of cases (some cited by Feduccia) in which the avian status of particular specimens is still a matter for debate. It is probably for these reasons that while popular books on dinosaurs are legion, a book on bird palaeontology is unusual despite the innumerable amateur ornithologists that are the mainstay of almost every natural history society. One would hope, therefore, that there was a market for a popular book like Feduccia's as evidence that at least some of these amateurs have interests extending beyond the prevalent stamp-collecting approach to bird watching.

On the whole Feduccia serves his potential audience well. However, his opening chapter tends to hop about its subject matter in a manner reminiscent of small birds themselves, starting with a scene-setting paragraph on Archaeopteryx - geologically the oldest as well as the most famous of all bird fossils - but then switching to bird anatomy, "Darwin's finches", adaptive radiation, the concepts of homology and analogy, the reconstruction of phylogeny and the geological time scale, before settling on an account of the several finds of Archaeopteryx, with useful photographs of each specimen.

In his second chapter he gives an account of theories of the evolutionary origin of birds, a fiercely debated subject still. When dealing with controversial issues Feduccia is usually sensible and it is not his fault that at least one of the principal protagonists in this debate has changed sides since the chapter was written. Following chapters deal with the evolution of flight and then with the fossil history (such as it is) and evolution of all the major groups of birds.

Feduccia has been in the forefront of some of the phylogenetic work he describes and much of the book is authoritative. However, particularly in the early chapters, there are some things to take exception to. The layman's naive view of the course of evolution, as a highway from simple organisms to human beings with less important byways branching off, will be reinforced by statements such as "ornithischians [a dinosaur group] were highly specialised herbivores and far too removed from the main line to have given rise to any other major group"'. It will be similarly reinforced by the use of "Age of Reptiles", "Age of Mammals and Birds" and so on, as in "The cotylosaurs [the earliest reptiles in the author's (outmoded) usagel appeared long before the Age of Reptiles ...". There are also a few obvious errors - how, for example, can the two views of the original Archaeopteryx feather, pictures on p.12, be "main slab" and "counterslab" when they are not mirror images of one another? Also, the patagium (flying membrane) of the living flying lizard genus Draco does not stretch "between the forelimb and hindlimb" (p.40): it is supported by elongate ribs alone.

On the whole, though, the book is easy and pleasant to read. The style is clear, concise and interesting, albeit with some infelicities - "Members of this classifica- 